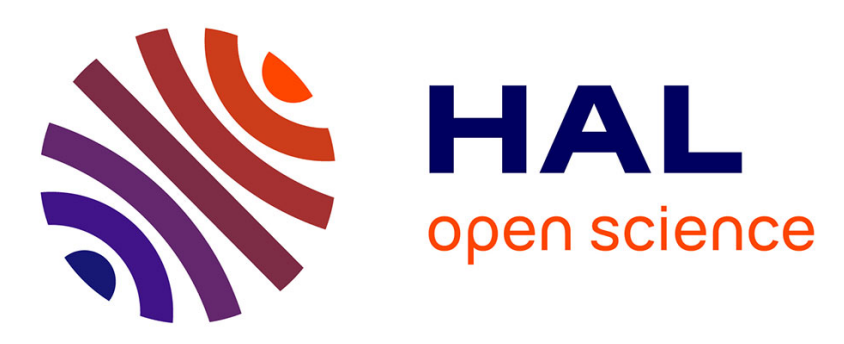

\title{
Subject-specific numerical estimation of the temporomandibular joint reaction force during mouth opening and closing movements
}

Emilie Sapin - de Brosses, Diego Alvarez Areiza, Anne-Sophie Bonnet, Paul Lipinski

\section{To cite this version:}

Emilie Sapin - de Brosses, Diego Alvarez Areiza, Anne-Sophie Bonnet, Paul Lipinski. Subject-specific numerical estimation of the temporomandibular joint reaction force during mouth opening and closing movements. Computer Methods in Biomechanics and Biomedical Engineering, 2011, 36th Congress of the Société de Biomécanique, 14 (sup1), pp.125-127. 10.1080/10255842.2011.593764 . hal-03181957

\section{HAL Id: hal-03181957 \\ https://hal.science/hal-03181957}

Submitted on 26 Mar 2021

HAL is a multi-disciplinary open access archive for the deposit and dissemination of scientific research documents, whether they are published or not. The documents may come from teaching and research institutions in France or abroad, or from public or private research centers.
L'archive ouverte pluridisciplinaire HAL, est destinée au dépôt et à la diffusion de documents scientifiques de niveau recherche, publiés ou non, émanant des établissements d'enseignement et de recherche français ou étrangers, des laboratoires publics ou privés. 


\title{
Subject-specific numerical estimation of the temporomandibular joint reaction force during mouth opening and closing movements
}

\author{
E. SAPIN - DE BROSSES $\dagger^{*}$, D. ALVAREZ AREIZA $\uparrow$, A-S BONNET $\dagger$ and P. LIPINSKI $\dagger$ \\ $\uparrow$ Laboratory of mechanics, Biomechanics, Polymers, Structure, National Engineering School of \\ Metz, Paul Verlaine University, 1 route d'Ars Laquenexy METZ, FRANCE.
}

Keywords: Biomechanics; Temporomandibular joint, Kinematics, Joint reaction force, Muscular contribution

\section{Introduction}

The temporomandibular joint (TMJ) is composed by the mandibular condyle, the temporal fossa and an articular disc in between. The TMJ can be seriously damaged as a result of bone or dental disorders. To perform joint reconstruction and design prostheses, there is a need to better understand the TMJ 3D kinematics to estimate the joint reactions and disc contribution. In the literature, mandibular movements were used to describe TMJ kinematics but the studies have been carried out on small groups $(<30)$ [1-4]. Besides, coupled studies of TMJ kinematics and dynamics are rather rare. Finally, no comparison of healthy and pathological subjects was done. This work aims to analyze TMJ kinematics and dynamics for large groups of asymptomatic and toothless subjects.

\section{Method}

\subsection{Kinematic analysis}

The Win Jaw Analysis ultrasound-based system (Zebris $\mathrm{GmbH}$ ) was used to capture jaw movements. The transmitting sensor was fixed on the lower anterior teeth and the receiver sensor was attached to the head (Figure 1). Opening - closing, laterotrusion and protrusion - retrusion movements were repeated 5 times. These movements were expressed in the Camper's skull frame [1].

Condylar rotation around the initial intercondylar axis, and condylar translation along the posteroanterior axis were quantified. The trajectories of the left and right condyles and incisal point were studied in the three planes of the morphological skull frame.

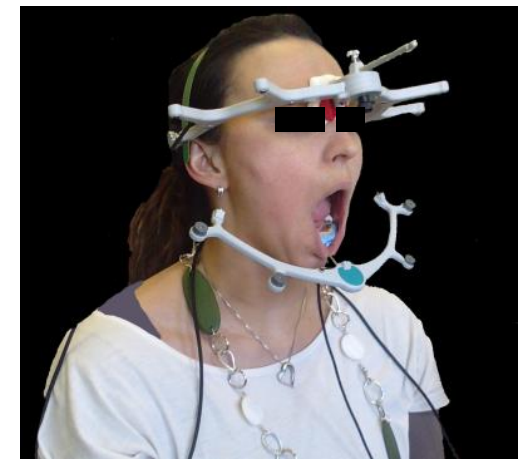

Figure 1. Win Jaw Analysis device for kinematics analysis of jaw movements

\subsection{Numerical modelling of the TMJ}

\section{Subject-specific mesh}

The subject-specific 3D geometries of the temporal fossae and the mandible were obtained using quantitative computed tomography (QCT). The inertial properties of the mandible were computed from the geometry and the Hounsfield units assessed on the QCT slices (3Matic 2 and Mimics 7.3, Materialise, Leuven, Belgium).

\section{Modelling of the muscular contribution}

Muscles were added to the 3D model of the fossae and mandible using LifeMOD v.2008 (MSC Software Corporation) (Figure 2). Hill - type muscles were considered. Muscular insertions were defined according to anatomical data and the muscular properties (cross sectional area and maximal force) were taken from Perez del Palomar and Doblare [5]. Using an inverse method, a value of the force developed by each muscle was computed from the 3D movement of the mandible relative to the skull, which was previously recorded on the same subject.

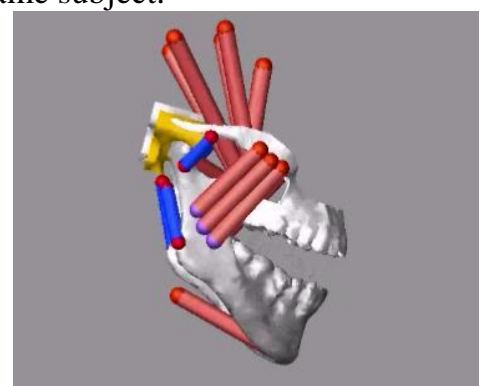

Figure 2. 3D Modelling of the TMJ environment (LifeMOD software)

Contact algorithm: joint reaction force calculation The temporal fossa and the articular disc were considered as a single body. The contact characteristics (stiffness $\mathrm{k}$, viscosity $\mathrm{c}_{\max }$, full damping depth $\mathrm{d}_{\max }$, hyperelastic exponent e) between the condyles and the fossae were deduced from the works of Beek et al and Tanaka et al. concerning disc properties [6-7].

The total joint reaction force was calculated from the amount of penetration $(\mathrm{g})$ during the mandible motion:

$$
F_{n}=k \cdot(g)^{e}+\operatorname{STEP}\left(g, 0,0, d_{\text {max }}, c_{\text {max }}\right) \frac{d g}{d t}
$$




\section{Results and Discussion}

Results are presented for one healthy woman (32 years old) without dental and TMJ disorders (no trauma and no pain). Comfortable opening-closing movements corresponded to a range of vertical motion of $23.0 \pm 5.1 \mathrm{~mm}$ for the incisal point (Table 1). The ratio of rotation vs translation during the movement was consistent with the middle group, defined by Coutant et al. [1], characterized by a two-phase movement: a concomitant rotation and translation movement followed by a quasi-pure rotation.

\begin{tabular}{|c|c|c|c|c|}
\hline Trial & $\begin{array}{c}\text { Opening } \\
\text { amplitude } \\
(\mathrm{mm})\end{array}$ & $\begin{array}{c}\text { Condylar } \\
\text { anterior } \\
\text { translation } \\
(\mathrm{mm})\end{array}$ & $\begin{array}{c}\text { Rotation around } \\
\text { intercondylar axis } \\
\left({ }^{\circ}\right)\end{array}$ & $\begin{array}{c}\text { Rotation/ } \\
\text { translation } \\
\text { ratio } \\
(\% / \mathrm{mm})\end{array}$ \\
\hline 1 & $-21,8$ & 5,5 & 12,7 & 2,3 \\
\hline 2 & $-27,9$ & 7,6 & 17,6 & 2,3 \\
\hline 3 & $-28,6$ & 8,6 & 18,2 & 2,1 \\
\hline 4 & $-16,7$ & 2,4 & 10,2 & 4,2 \\
\hline 5 & $-20,3$ & 4,4 & 11,8 & 2,7 \\
\hline Mean & $\mathbf{- 2 3 , 0}$ & $\mathbf{5 , 7}$ & $\mathbf{1 4 , 1}$ & $\mathbf{2 , 7}$ \\
\hline SD & $\mathbf{5 , 1}$ & $\mathbf{2 , 5}$ & $\mathbf{3 , 6}$ & $\mathbf{0 , 9}$ \\
\hline
\end{tabular}

Table 1. Kinematic values for comfortable mouth opening

The numerical analysis of muscles contribution was done for a comfortable opening and a maximal mouth opening (vertical displacement of the incisal point equal to $17 \mathrm{~mm}$ and $48 \mathrm{~mm}$ respectively). The numerical solution suggested that the closing movement was mainly driven by the masseter and temporal muscles. The medial pterigoid had a small contribution and the lateral pterogoid did not participated to this movement at all. This muscular recruitment was consistent with the EMG activity reported in physiological studies of the opening movements [8-9]. To date, it is however not possible to validate the values of the muscular forces.

The total joint reaction force was equal to $4 \mathrm{~N}$ for the comfortable opening and $17 \mathrm{~N}$ for the maximal opening. These values are consistent with the dynamic simulations of Peck et al [10] (between 10 and $28 \mathrm{~N}$ ). Our findings were hardly dependent on the contact properties which should be refined to be closer to the physiological behaviour of the articular disc. Moreover, the study gives results for one subject and should be carried out on a large group for statistical significance.

\section{Conclusions}

This study proposed a numerical approach to compute the subject-specific TMJ dynamics and total joint reaction forces. This method provided a physiologically acceptable solution for the muscular recruitment. However, the contact definition should be refined and these results should be confirmed on a larger group. For this reason, a study of 30 healthy subjects and 5 toothless subjects with their artificial denture (implants and dental prostheses) is being carried out following the same protocol. The comparison between these groups could help to better understand temporomandibular disorders.

\section{References}

[1] Coutant J-C, Mesnard M, Morlier J et al. Discrimination of objective kinematic characters in temporomandibular joint displacements. Archives of Oral Biology. 2008. 53 : 453-461.

[2] Ferrario V, Sforza C, Lovecchio N et al. Quantification of translational and gliding components in human temporomandibular joint during mouth opening. Archives of oral Biology. 2005. 50: 507-515.

[3] Leader J.K., Boston J.R., Debski R.E., et al. Mandibular kinematics represented by a nonorthogonal floating axis joint coordinate system. Journal of Biomechanics. 2003. 36: 275-281.

[4] Tuijt M, Koolstra JH, Lobbezoo F, et al. Differences in loading of the temporomandibular joint during opening and closing of the jaw. Journal of Biomechanics. 2010. 43: 1048-1054.

[5] Perez del Palomar A and Doblare.M. Dynamic 3D FE modelling of the human TemporoMandibular Joint during whisplash. Medical Engineering \& Physics. 2008. 30: 700709.

[6] Beek M, Aarnts MP, Koolstra JH et al. Dynamic Properties of Human Temporomandibular Joint Disc. Research Reports, Biomaterials and Bioengineering. Journal of Dental Research. 2001. 80(3): 876-880.

[7] Tanaka E, Kawai N, Tanaka M. et al. The frictional coefficient of the temporomandibular joint and its dependency on the magnitude and duration of joint loading. Journal of Dental Research. 2004. 83: 404-407.

[8] Dufour M..and Pillu M.. Biomecanique fonctionnelle. Membre - Tête - Tronc. 2005. Ed Masson.

[9] Møller, E. The chewing apparatus. An electromyographic study of the action of the muscles of mastication and its correlation to facial morphology. Acta Physiologica Scandinavica. 1966. Supplement 260, 1-229

[10] Peck C.C., Langenbach G.E.J, Hannam A.G. Dynamic simulation of muscle and articular properties during human wide jaw opening. Archives of Oral Biology. 2000. 45, 96382

\section{Acknowledgments}

The authors wish to thank Cynthia Dreistadt and Deborah Cristina Jahn for their contribution to the measurements 